\title{
Upstream molecular signaling pathways of p27 (Kip1) expression in human breast cancer cells in vitro: differential effects of 4-hydroxytamoxifen and deficiency of either D-(+)-glucose or L-leucine
}

Isao Eto

\begin{abstract}
Background: The objective of this study was to investigate whether the levels of glucose or certain amino acids could regulate the expression of a cell cycle repressor protein p27(Kip1), thereby dictating the risk of cancer in either obesity or caloric/dietary restriction. Previously, we identified and reported four different upstream molecular signaling pathways of p27 expression in human breast cancer cells. We called these four pathways as pathway \#1, \#2, \#3 and \#4. We found that 4-hydroxytamoxifen - but not tamoxifen - up-regulated the expression of p27 using pathway \#1 which consisted mainly of receptor tyrosine kinases and mTORC1. We now investigate, using 4hydroxytamoxifen as a reference anti-cancer agents, whether (a) the moderate increase in the concentration of D(+)-glucose could down-regulate and, conversely, (b) the deficiency of D-(+)-glucose or certain L-amino acids could up-regulate the expression of p27 in these cells using pathway \#2 which consists mainly of AMPK and mTORC1.

Results: Using human MDA-MB-231 breast cancer cells in vitro, these hypotheses were tested experimentally by performing p27-luciferase reporter transfection assays and western immunoblot analyses. The results obtained are consistent with these hypotheses. Furthermore, the results indicated that, although 4-hydroxytamoxifen used primarily pathway \#1 to down-regulate the phosphorylation of 4E-BP1 and up-regulate the expression of p27, it also secondarily down-regulated the phosphorylation of S6K1. In contrast, the deficiency of D-(+)-glucose or Lleucine used primarily pathway \#2 to down-regulate the phosphorylation of S6K1, but they also secondarily downregulated the phosphorylation of 4E-BP1 and up-regulated the expression of p27. Finally, deficiency of D(+)-glucose or L-leucine - but not 4-hydroxytamoxifen - up-regulated the expression of mitochondrial ATP5A and SIRT3.
\end{abstract}

Conclusions: (a) 4-Hydroxitamoxifen used primarily pathway \#1 to up-regulate the expression of p27. (b) Moderate increase in the concentration of D-(+)-glucose used primarily pathway \#2 to down-regulate the expression of p27.

(c) Deficiency of D-(+)-glucose or L-leucine also used primarily pathway \#2 to up-regulate the expression of p27.

(d) Deficiency of D-(+)-glucose or L-leucine - but not 4-hydroxytamoxifen - up-regulated the expression of mitochondrial ATP5A in the Complex $V$ of respiratory oxidation-phosphorylation chain and mitochondrial SIRT3. The SIRT3 is one of the seven mammalian anti-aging as well as anti-metabolic sirtuins.

Correspondence: eto@@uab.edu

Department of Nutrition Sciences, University of Alabama at Birmingham, Birmingham, Alabama, USA 


\section{Background}

The risk of developing cancer is increased in obesity where the serum levels of glucose, certain amino acids, insulin and other growth factors tend to be elevated. Conversely, the risk of developing cancer is decreased in caloric/dietary restriction where the serum levels of these metabolites tend to be reduced. The objective of this study was to investigate whether the levels of glucose or certain amino acids could regulate the expression of a cell cycle repressor protein p27(Kip1), thereby dictating the risk of cancer in either obesity or caloric/ dietary restriction.

p27 is a member of the family of cyclin-dependent kinase (CDK) inhibitors (CDIs). p27 binds to certain cyclin/CDK complexes, arrests the cell cycle progression from $\mathrm{G} 1$ to $\mathrm{S}$ phase and inhibit DNA replication. It is known that a relatively large number of nutritional and chemopreventive anti-cancer agents - including 4-hydroxytamoxifen - specifically up-regulate the expression of p27 in both estrogen receptor (ER)-positive and -negative human breast cancer cells in vitro [1,2]. It is also known that some other anti-cancer agents specifically up-regulate the expression of p27 in either ER-positive or -negative human breast cancer cells in vitro $[1,2]$.

p27 exhibits a set of unique characteristics that are not seen in other G1-to-S phase cell cycle regulatory proteins $[1,2]$. First, various anti-cancer agents specifically up-regulate the expression of p27 without directly affecting expression of other G1-to-S phase cell cycle regulatory proteins including INK4s, p57(Kip2), p21 (Cip1Waf1), D-type cyclins, cyclin E, cyclin A, CDK2, CDK4 and CDK6 [1-3]. Secondly, the degree of up-regulation of the expression of p27 in human breast cancer cell lines in vitro by these anti-cancer agents linearly and positively correlates with the degree of inhibition of methylnitrosourea (MNU)-induced rat mammary adenocarcinoma in vivo by the same anti-cancer agents [2]. This linear and positive correlation could not be held if a particular anti-cancer agent must be converted to an active metabolite in vivo in order to up-regulate the expression of $\mathrm{p} 27$. An example of such anti-cancer agent is tamoxifen which must be converted to 4-hydroxytamoxifen in vivo to specifically up-regulate the expression of p27. Lastly, unlike other G1-to-S phase cell cycle regulatory proteins, expression of p27 is not regulated at the level of transcription, but primarily at the level of translation. It was observed in the 1980s and 1990s that, during the progression of cell cycle, the level of p27 protein expression oscillated cyclically, but the level of p27 mRNA remained constant. This observation led investigators to suggest that, during the cell cycle, expression of p27 is regulated primarily at the level of translation [4-10]. It was also proposed that the expression of p27 during the progression of cell cycle could be regulated by various other post-translational mechanisms including ubiquitin-proteasome-induced degradation [11-14], complex formation [15], subcellular localization [16-21] and phosphorylation [21-23]. Based on the results of our previous studies [1,2], we believe that a large number of anti-cancer agents up-regulate the expression of $\mathrm{p} 27$ primarily by activating the rate of translation initiation of p27 mRNA.

Despite all these information, however, very little is known about the upstream molecular signaling pathways of how various anti-cancer agents specifically up-regulate the expression of p27 in human breast cancer cells in vitro. Previously, we identified and reported four different upstream molecular signaling pathways of p27 expression by using p27-luciferase reporter plasmids, western immunoblot analysis and numerous specific inhibitors and stimulators of p27 expression [1,2]. (We will call these four pathways as \#1, \#2, \#3 and \#4.).

We also reported previously that, in both ER-positive and -negative human breast cancer cells in vitro, 4hydroxytamoxifen (4-OH-tamoxifen) - but not tamoxifen - up-regulated the expression of p27 by using pathway \#1 which consists mainly of receptor tyrosine kinases (RTKs) and mammalian target of rapamycin complex 1 (mTORC1) [2].

We now hypothesize that moderate increase in the concentration of D-(+)-glucose down-regulates the expression of p27 in human breast cancer cells in vitro by using pathway \#2 which consists mainly of 5 '-AMPactivated protein kinase (AMPK) and mTORC1. Conversely, we also hypothesize that deficiency of $\mathrm{D}-(+)$-glucose or certain L-amino acids up-regulates the expression of p27 in these cells by using the pathway \#2

To test these hypotheses, we performed p27-luciferase reporter transfection assays and western immunoblot analyses using ER and LKB1-double negative human MDAMB-231 breast cancer cell in vitro. The results obtained were consistent with these hypotheses. Additional results were also obtained that indicated that deficiency of D(+)-glucose or L-leucine - but not 4-hydroxytamoxifen up-regulated the expression of mitochondrial ATP Synthase $\alpha$ chain (ATP5A) in the Complex V of respiratory oxidation-phosphorylation chain and mitochondrial SIRT3 in these cells. The SIRT3 is one of the seven mammalian anti-aging and anti-metabolic sirtuins.

\section{Results}

4-Hydroxytamoxifen - but not tamoxifen - up-regulated the expression of p27 in estrogen receptor (ER) and LKB1-double negative human MDA-MB-231 breast cancer cells in vitro

The effects of 4-hydroxytamoxifen (4-OH-tamoxifen) and tamoxifen on the expression of p27 in human breast cancer cells in vitro were investigated using p27- 
luciferase reporter plasmids containing the following proximal 5'-upstream regions of $p 27$ gene, namely -1797 p27 (p27-Kpn I), -774 p27 (p27-Apa I), and -575 p27 (p27-5'UTR) (Figure 1a). These plasmids were transfected into ER and LKB1-double negative human MDAMB-231 breast cancer cells in vitro and then the transfected cells were exposed to DMSO or $1 \mu \mathrm{M}$ each of tamoxifen or 4-OH-tamoxifen for 24 hours. The results indicated that tamoxifen did not up-regulate the relative luciferase activity of p27 (Figure 1b), but 4-OH-tamoxifen up-regulated it in these cells (Figure 1c). Previously, we reported essentially the same results using ER and LKB1-double positive human MCF7 breast cancer cells in vitro $[1,2]$.

Additionally, the results of these studies, along with those of our previous studies [1,2], were consistent with the hypothesis that the expression of p27 is regulated primarily at the level of translation. For more information about this issue, please go to the Methods section below,

Based on these results, we constructed a schematic diagram (Figure 1d) showing the outline of how 4-OHtamoxifen could up-regulate the expression of $\mathrm{p} 27$, down-regulate the cell cycle progression from G1 to S phase, thereby inhibiting the DNA replication of the human breast cancer cells in vitro.

\section{Moderate increase in the concentration of D-(+)-glucose down-regulated the expression of p27, and, conversely, deficiency of D-(+)-glucose, L-leucine, L-methionine, L- cysteine or combination of L-methionine and L-cysteine up-regulated the expression of p27 in human MDA-MB- 231 breast cancer cells in vitro}

The effects of (a) moderate increase in the concentration of D-(+)-glucose and (b) deficiency of D-(+)-glucose, L-leucine, L-methionine, L-cysteine or combination of L-methionine and L-cysteine on the expression of p27 in MDA-MB-231 cells were investigated using one of the luciferase reporter plasmids containing a proximal 5'-upstream region of $p 27$ gene (-575 p27-5'UTR) (Figure 2a).

The results indicated that moderate increase in the concentration of D-(+)-glucose down-regulated the relative luciferase activity of -575 p27-5'UTR in MDA-MB231 cells (Figures $2 \mathrm{~b}$ ). In contrast, deficiency of D(+)-glucose, L-leucine, L-methionine, L-cysteine or combination of L-methionine and L-cysteine up-regulated the relative luciferase activity of p27 in these cells (Figure 2c). It should be noted that deficiency of the combination of L-methionine and L-cysteine up-regulated the relative luciferase activity of p27 more than the deficiency of individual amino acids.

The results (Figure 2b) also indicated that (a) rotenone (inhibitor of NADH dehydrogenase (Complex 1) of the mitochondrial respiratory oxidation-phosphorylation chain) and AICA riboside (inhibitor of AMPK (5'-AMPactivated protein kinase)) up-regulated the relative luciferase activity of p27 in MDA-MB-231 cells, but (b) compound $\mathrm{C}$ (activator of $\mathrm{AMPK}$ ) down-regulated the relative luciferase activity of p27 in these cells. Metformin did not either up or down-regulate the relative luciferase activity of p27 probably because MDA-MB-231 cells lack LKB1.

\section{Differential effects of 4-hydroxytamoxifen and deficiency of D-(+)-glucose on the upstream molecular signaling pathways of the expression of p27: pathways immediately downstream of mTORC1 (mammalian target of rapamycin complex 1 )}

Previously, we identified and reported four different upstream molecular signaling pathways of p27 expression that could lead to either activation or inactivation of the translation initiation of p27 mRNA through its unusually long 5'-untranslated region (5'-UTR) (-575) of p27 mRNA (Figure 3a and 3b) [2]. We also reported previously that 4-hydroxytamoxifen (4-OH-tamoxifen) up-regulated the expression of p27 by using pathway \#1 which consists mainly of receptor tyrosine kinases (RTKs) and mTORC1 (Figure 3a) [2]. We now hypothesize that (a) moderate increase in the concentration of D-(+)-glucose down-regulates and, conversely, (b) deficiency of D-(+)-glucose or certain L-amino acids up-regulates the expression of p27 by using pathway \#2 which consists mainly of AMPK (5'-AMP-activated protein kinase) and mTORC1 (mammalian target of rapamycin complex 1) (Figure 3a).

To begin to test these hypotheses, we first performed the western immunoblot analysis of the expression of p27 protein itself. The results (Figures 3c, d and 3e) indicated that 4-OH-tamoxifen and deficiency of D(+)-glucose or L-leucine up-regulated the expression of p27 protein, but deficiency of L-methionine or Lcysteine did not in MDA-MB-231 cells.

In order to look more closely into the effects of 4$\mathrm{OH}$-tamoxifen and deficiency of D-(+)-glucose or certain L-amino acids on the upstream molecular signaling pathways \#1 and \#2 of the expression of p27, western immunoblot analyses were performed to investigate the proteins immediately downstream of mTORC1, namely eukaryotic translation initiation factor $4 \mathrm{E}$ binding protein 1 (4E-BP1) and p70 S6 kinase 1 (S6K1).

\section{(a) Differential effects on the phosphorylation of $4 E-B P 1$}

Figure $4 \mathrm{a}$ to $4 \mathrm{e}$ show that (a) 4-OH-tamoxifen and (b) deficiency of D-(+)-glucose or L-leucine did not either down or up-regulate the expression of total 4E-BP1, but they down-regulated the phosphorylated 4E-BP1. As summarized in Figure 4f, the degree of down-regulation of the phosphorylated 4E-BP1 appeared to be positively 


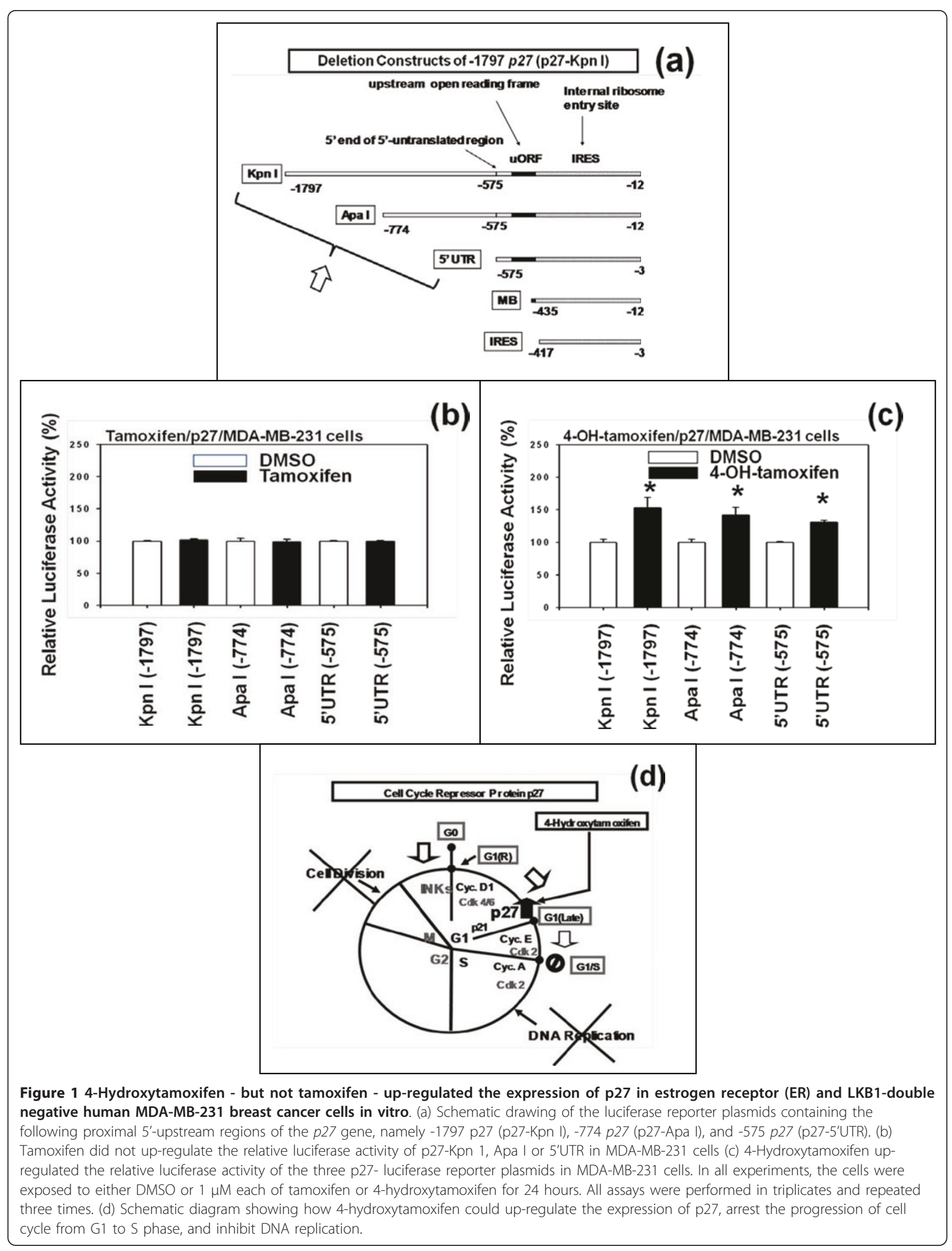




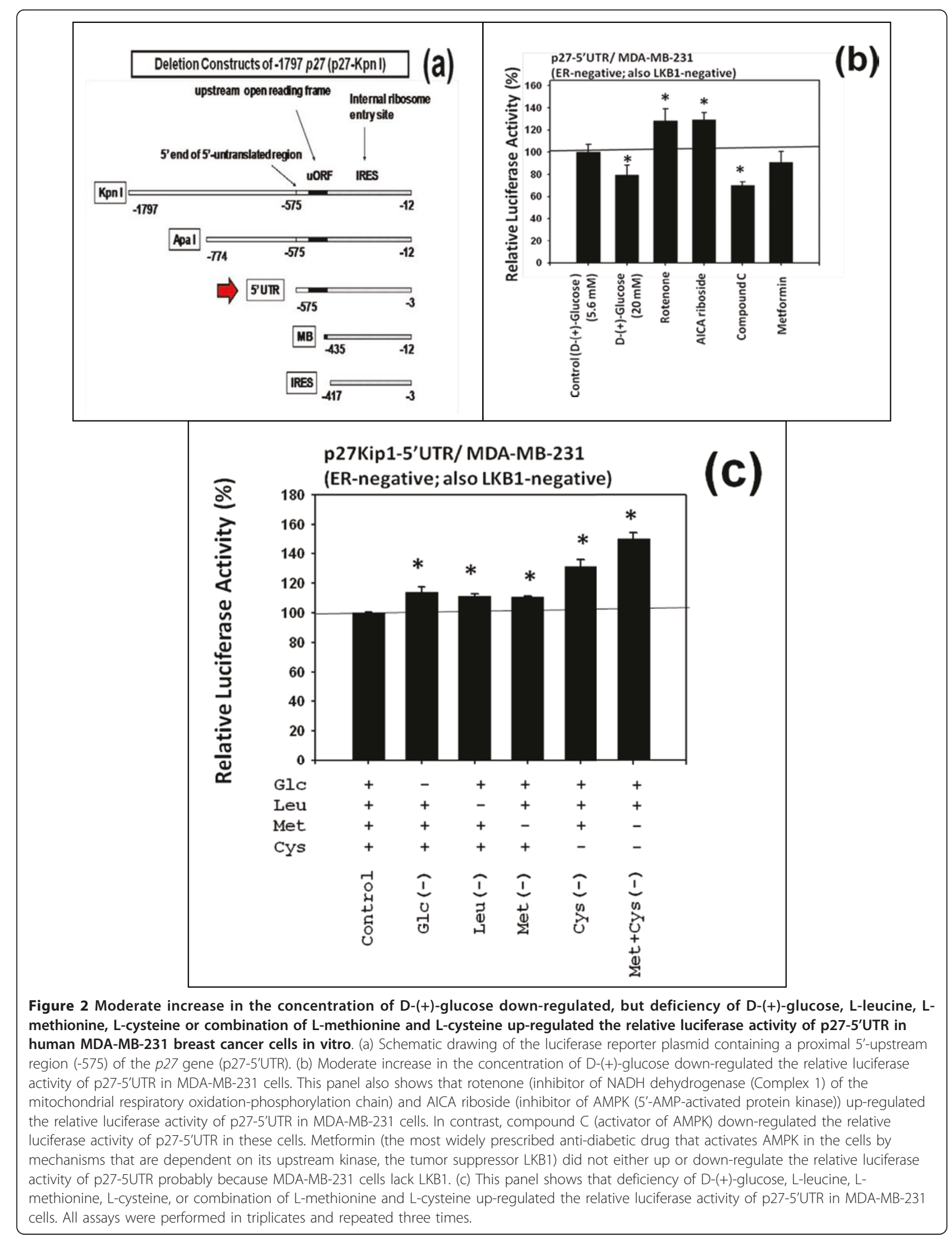




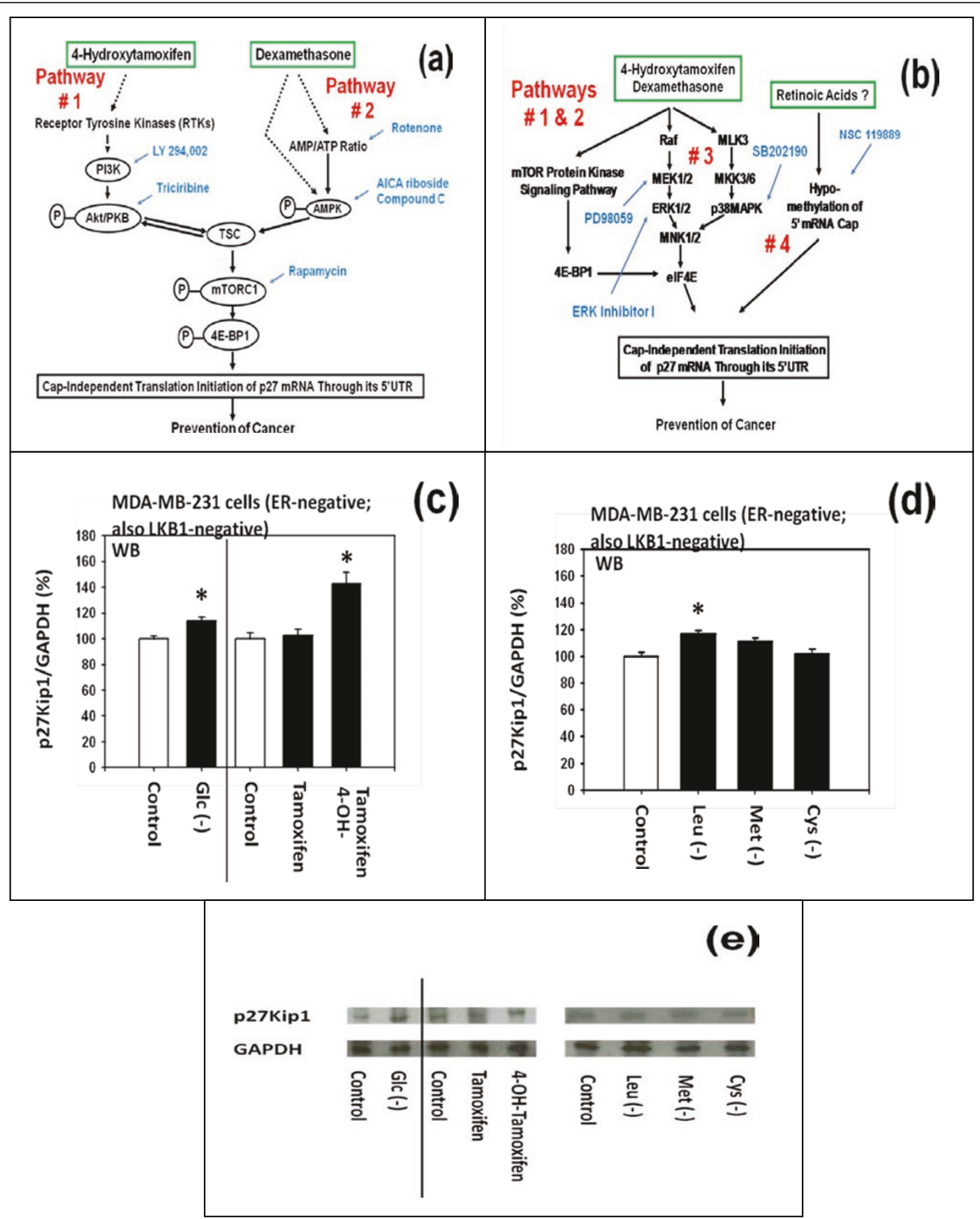

Figure 3 Schematic diagram of the four different upstream molecular signaling pathways of p27 expression that could lead to either increased or decreased expression of p27 in human breast cancer cells in vitro. (a) Previously, we identified and reported four different upstream molecular signaling pathways of the expression of p27 [1,2]. We also reported previously that 4-hydroxytamoxifen - but not tamoxifen - up-regulated the expression of p27 by using pathway \#1 which consists mainly of receptor tyrosine kinases (RTKs) and mTORC1 [2]. Now, we hypothesize that (i) moderate increase in the concentration of D-(+)-glucose down-regulates and (ii) deficiency of D-(+)-glucose or certain Lamino acids up-regulates the expression of p27 using pathway \#2 which consists mainly of AMPK and mTORC1. (b) We also identified and reported previously two additional upstream molecular signaling pathways - namely \#3 and \#4 - of the expression of p27 [1,2]. (c and e) Western immunoblot analysis of the effects of D-(+)-glucose deficiency, DMSO, tamoxifen and 4-hydroxytamoxifen on the expression of p27 protein in MDA-MB-231 cells. ( $d$ and e) Western immunoblot analysis of the effects of the deficiency of L-leucine, L-methionine or L-cysteine on the expression of p27 protein in these cells. All assays were performed in triplicates and repeated three times. 


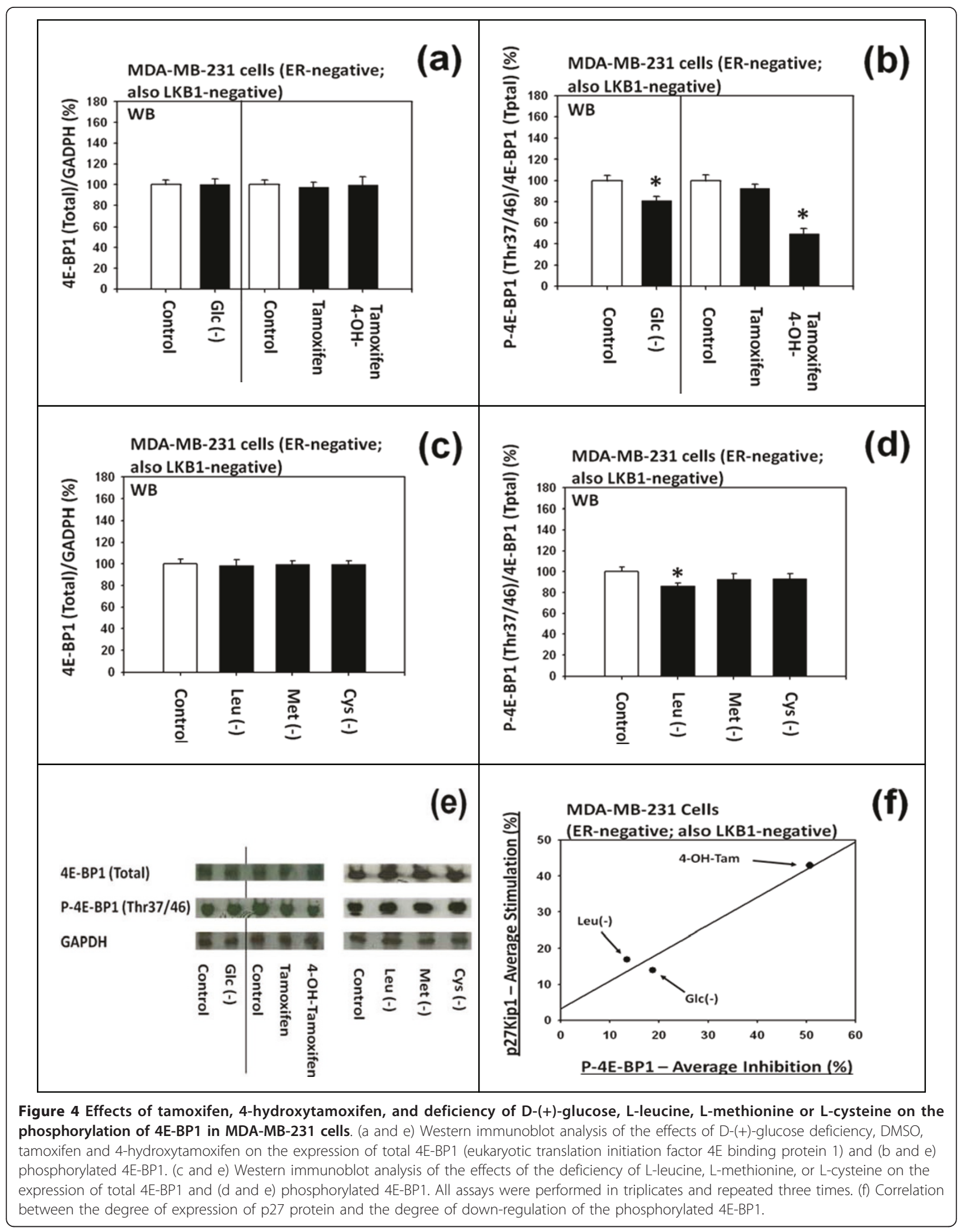


and linearly correlated with the degree of expression of p27.

\section{(b) Differential effects on the phosphorylation of S6K1}

Figure $5 \mathrm{a}$ to $5 \mathrm{e}$ show that (a) 4-OH-tamoxifen and (b) deficiency of $\mathrm{D}-(+)$-glucose, L-leucine or L-methionine did not influence the expression of total S6K1, but they down-regulated the phosphorylated S6K1. As summarized in the Figure $5 \mathrm{f}$, the degree of down-regulation of the phosphorylated S6K1 did not appear to be correlated with the degree of expression of p27.

It should be noted that (a) 4-OH-tamoxifen and (b) deficiency of $\mathrm{D}-(+)$-glucose or certain L-amino acids exerted differential effects on the degree of downregulation of either the phosphorylated 4E-BP1 or phosphorylated S6K1. For example, (a) 4-OH-tamoxifen preferentially down-regulated the phosphorylation of 4E-BP1 over S6K1. Conversely, (b) D$(+)$-glucose deficiency preferentially down-regulated the phosphorylation of S6K1 over 4E-BP1. (c) L-Leucine deficiency significantly down-regulated the phosphorylation of both 4E-BP1 and S6K1, but to a much lesser extent. (d) L-Methionine deficiency significantly down-regulated the phosphorylation of only S6K1 and to a much lesser extent; but it did not significantly down-regulate the phosphorylation of 4E-BP1. Lastly, (e) L-cysteine deficiency did not significantly down-regulate the phosphorylation of either 4E-BP1 or S6K1.

Differential effects of 4-hydroxytamoxifen and deficiency of D-(+)-glucose on the upstream molecular signaling pathways of p27 expression: pathways further downstream of mTORC1

Next, we investigated the effects of tamoxifen, 4-OHtamoxifen, and the deficiency of D-(+)-glucose on the pathways further downstream of mTORC1. They were (a) hypoxia-inducible factor $1 \alpha$ (HIF-1 $\alpha$ ), (b) sterol regulatory element binding protein-1 (SREBP-1) and (c) phosphorylation of eukaryotic elongation-factor-2 kinase (eEF2k). The results of the western immunoblot analyses are presented in Figure 6a to 6e. The effects of L-amino acid deficiencies were not investigated because they exerted either only a moderate or no effect on the phosphorylation of 4E-BP1 or S6K1.

\section{(a) Differential effects on HIF-1 $\alpha$}

HIF- $1 \alpha$ has been variably characterized in the literature as being a protein downstream of 4E-BP1, S6K1 or both. The results of our western immunoblot analyses presented in Figure 6a and 6e indicated that D-(+)-glucose deficiency significantly down-regulated the expression of HIF-1 $\alpha$; but 4-OH-tamoxifen did not. These results are consistent with the hypothesis that HIF-1 $\alpha$ is a protein primarily downstream of S6K1.

\section{(b) Differential effects on SREBP-1 and phosphorylated eEF2k}

No controversy exists in the literature as to the SREBP1 and eEF2k; the consensus is that they are the proteins primarily downstream of S6K1. The results of our western immunoblot analyses of SREBP1 (Figure $6 \mathrm{~b}$ and $6 \mathrm{e}$ ) and phosphorylated eEF2k at Ser366 (Figure 6c, d and $6 \mathrm{e})$ are consistent with this consensus.

Differential effects of 4-hydroxytamoxifen and deficiency of D-(+)-glucose or L-leucine on the upstream molecular signaling pathways of p27 expression: pathways upstream of mTORC1

The results presented above (Figure $2 \mathrm{~b}$ ) suggested that NADH dehydrogenase (Complex 1) in the mitochondrial respiratory oxidation-phosphorylation chain and 5'AMP-activated protein kinase (AMPK) are the two critical components of the pathway \#2 upstream of mTORC1. In addition to these two proteins, we investigated two other proteins that also appeared to be associated with the pathway \#2 upstream of mTORC1. They were mitochondrial ATP Synthase $\alpha$ chain (ATP5A) in the Complex V of respiratory oxidation-phosphorylation chain and mitochondrial SIRT3.

\section{(a) Differential effects on the mitochondrial ATP5A}

During our preliminary proteomic analysis of the hepatic proteins of genetically obese mice and long-lived dwarf mice, we observed that mitochondrial ATP5A was most significantly down-regulated in the liver of leptindeficient obese mice relative to the lean control mice. Conversely, we also observed that mitochondrial ATP5A was most significantly up-regulated in the liver of longlived Ames dwarf mice compared to the normal Ames mice. Based on these preliminary observations, we decided to investigate the effects of 4-OH-tamoxifen and deficiency of $\mathrm{D}-(+)$-glucose or certain L-amino acids on the expression of mitochondrial ATP5A in the human MDA-MB-231 breast cancer cells in vitro.

The results of our western immunoblot analyses (Figure $7 \mathrm{a}, \mathrm{b}$ and $7 \mathrm{e}$ ) indicated that 4-OH-tamoxifen did not influence the expression of mitochondrial ATP5A, but deficiency of D-(+)-glucose, L-leucine or L-methionine up-regulated it. Deficiency of L-cysteine did not alter the expression of mitochondrial ATP5A.

\section{(b) Differential effects on the mitochondrial SIRT3}

Mitochondrial SIRT3 is one of the seven mammalian anti-aging and anti-metabolic sirtuins. It was reported recently that mitochondrial ATP5A forms complex with and interacts with mitochondrial SIRT3 [24]. Based on this report, we decided to investigate the effects of 4-OHtamoxifen and deficiency of D-(+)-glucose or certain Lamino acids on the expression of mitochondrial SIRT3 in the human MDA-MB-231breast cancer cells in vitro. 


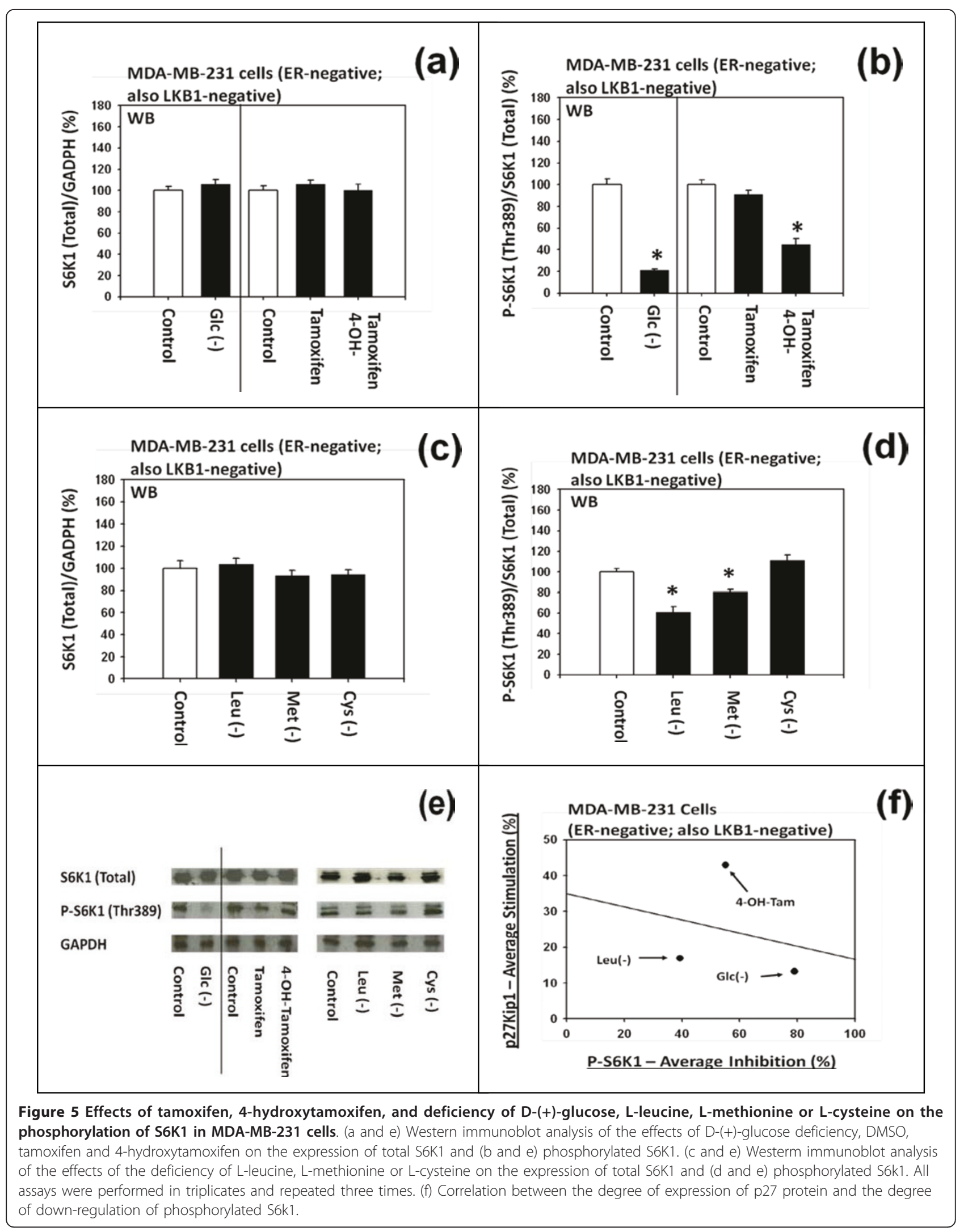




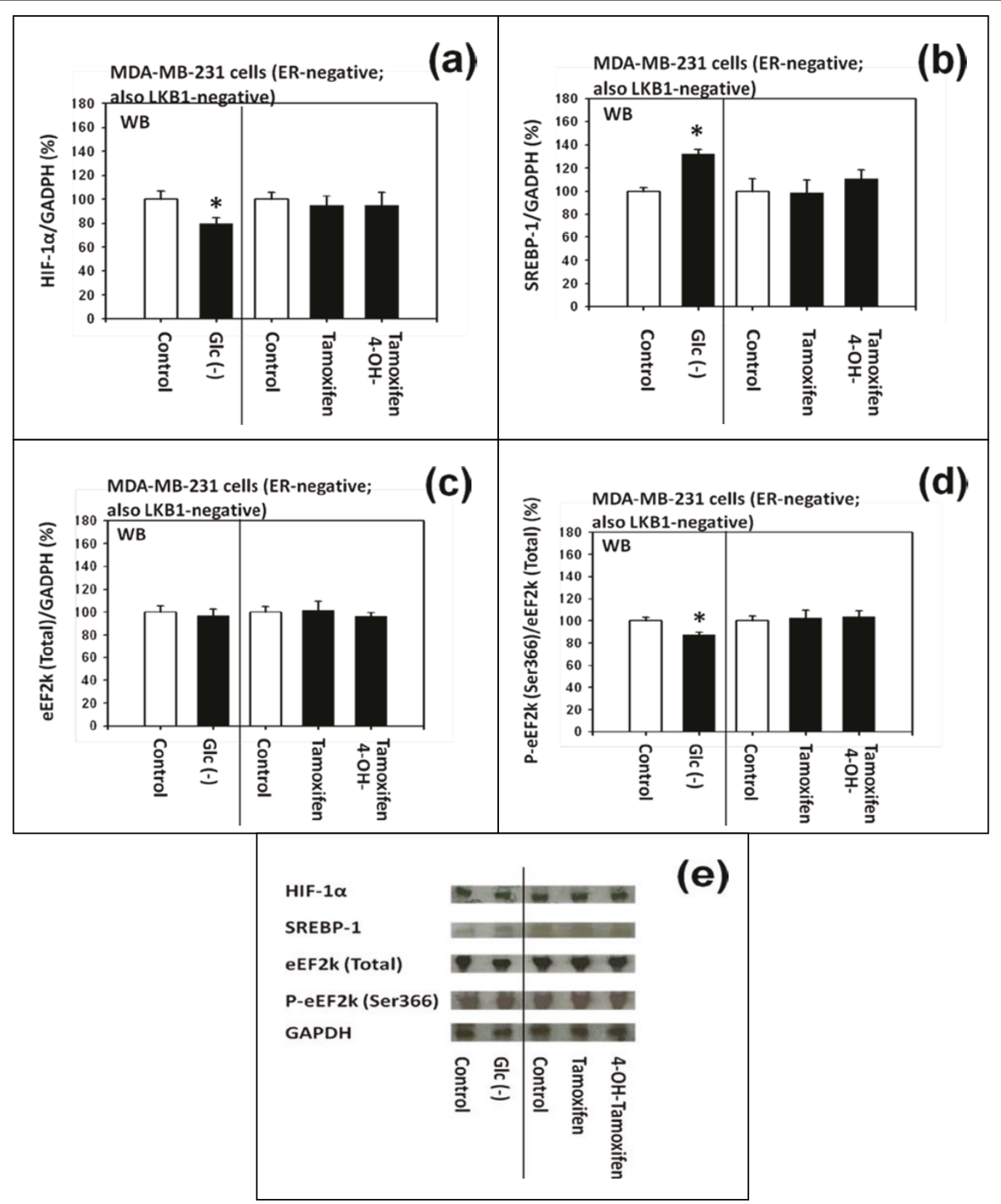

Figure 6 Effects of tamoxifen, 4-hydroxytamoxifen and deficiency of D-(+)-glucose on the expression of HIF-1a, SREBP-1 and phosphorylation of eEF2k in MDA-MB-231 cells. (a and e) Western immunoblot analysis of the effects of D-(+)-glucose deficiency, DMSO,

tamoxifen and 4-hydroxytamoxifen on the expression of HIF1 $\alpha$. ( $b$ and e) SREBP-1, (c and e) total eEF2k and ( $d$ and e) phosphorylated eEF2k. All assays were performed in triplicates and repeated three times.

The results of our western immunoblot analyses (Figure $7 \mathrm{c}, \mathrm{d}$ and $7 \mathrm{e})$ indicated that deficiency of D-(+)-glucose or L-leucine - but not 4-OH-tamoxifen - up-regulated the expression of mitochondrial SIRT3 in these cells. Deficiency of L-methionine or L-cysteine, however, did not either up or down-regulate the expression of SIRT3.

Finally, 4-OH-tamoxifen and deficiency of D-(+)-glucose or certain L-amino acids did not regulate the expression of nuclear anti-aging and anti-metabolic protein SIRT1 in these cells (results not shown).

\section{Discussion}

Based on the results presented above, a schematic diagram is presented in Figure 8 that outlines the effects of 4-hydroxitamoxifen, moderate increase in the concentration of $\mathrm{D}-(+)$-glucose and deficiency of $\mathrm{D}-(+)$-glucose or 


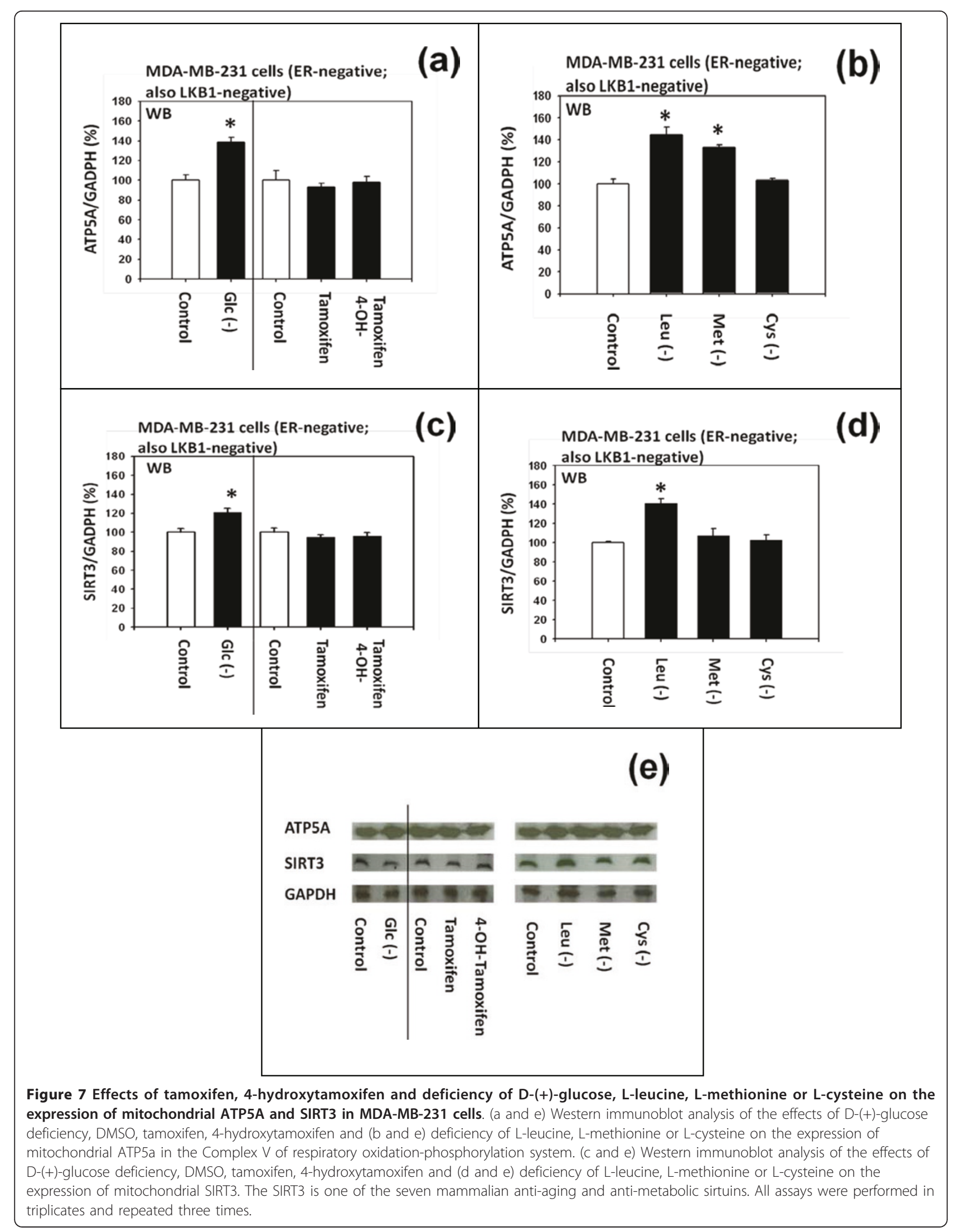




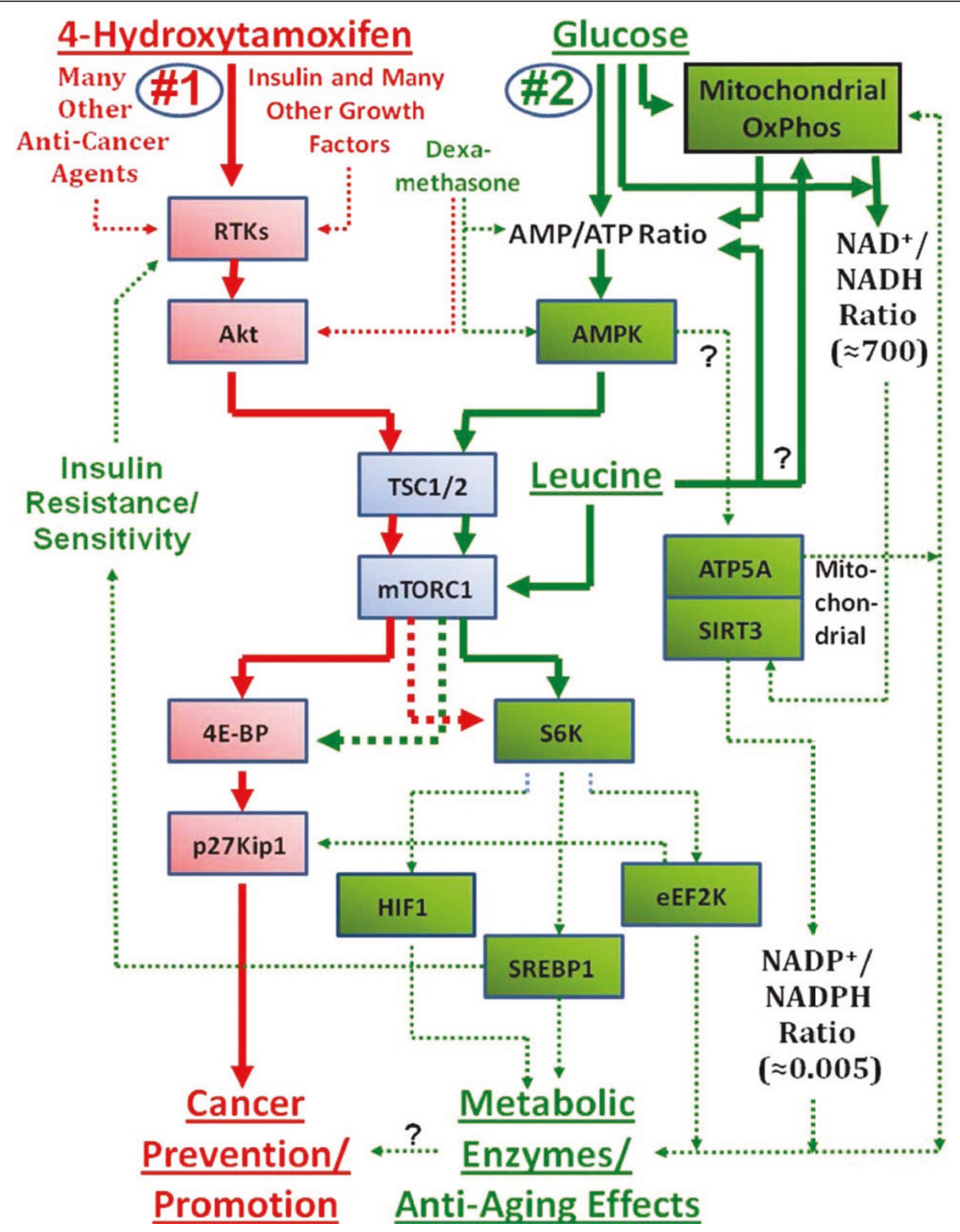

Figure 8 Schematic diagram of the hypothetical molecular signaling pathways of the expression of p27 by which moderate increase in the concentration of D-(+)-glucose down-regulates and deficiency of D-(+)-glucose or L-leucine up-regulates the expression of p27. This summary diagram shows the outline of how 4-hydroxytamoxifen uses primarily pathway \#1 to up-regulate the expression of p27, arrest the G1-to-S phase transition of cell cycle, and inhibit DNA replication in human breast cancer cells in vitro. 4-Hydroxytamoxifen preferentially phosphorylates 4E-BP1 over S6K1. The diagram also shows the outline of how the deficiency of D-(+)-glucose uses primarily pathway \#2 to upregulate the expression of p27, arrest the G1-to-S phase transition of cell cycle, and inhibit DNA replication in human breast cancer cells in vitro. D-(+)-Glucose deficiency preferentially phosphorylates S6K1 over 4E-BP1. The diagram also shows that the deficiency of L-leucine enters the pathway \#2 at points different from the deficiency of D-(+)-glucose. Finally, the diagram shows that deficiency of D-(+)-glucose or L-leucine uses L-upstream molecular signaling pathway \#2 of the expression of p27 to up-regulate the phosphorylation of AMPK and the expression of mitochondrial ATP5A and SIRT3. The mitochondrial SIRT3 exerts anti-aging and other metabolic effects on the cells. 
L-leucine on the pathways \#1 and \#2 of the upstream molecular signaling pathways of the expression of p27 in human breast cancer cells in vitro. The results presented are consistent with the following hypotheses, namely:

(a) 4-Hydroxitamoxifen up-regulates the expression p27 in human breast cancer cells in vitro primarily by using pathway \#1. The pathway \#1 consists mainly of receptor tyrosine kinases/phosphoinositide-3-kinase/ Akt/tuberous sclerosis complex/mammalian target of rapamycin complex 1 /eukaryotic translation initiation factor $4 \mathrm{E}$-binding protein 1 (RTKs/PI3K/Akt/TSC/ mTORC1/4E-BP1).

(b) Moderate increase in the concentration of D$(+)$-glucose or certain amino acids down-regulates and deficiency of D-(+)-glucose or L-leucine up-regulates the expression of p27 in human breast cancer cells in vitro primarily by using pathway \#2. The pathway \#2 consists mainly of 5'-AMP-activated protein kinase/ tuberous sclerosis complex/mammalian target of rapamycin complex 1/p70 S6 kinase I (AMPK/TSC/ mTORC1/S6K1). The pathway \#2 also modulates the phosphorylation of $4 \mathrm{E}-\mathrm{BP} 1$ thereby regulating the expression of $\mathrm{p} 27$, but this effect is secondary to its effect on the phosphorylation of S6K1.

Down-regulation of the phosphorylation of S6K1 in the pathway \#2 by the deficiency of $\mathrm{D}-(+)$-glucose resulted in the (i) down-regulation (de-stabilization) of HIF-1 $\alpha$, (ii) up-regulation (stabilization) of SREBP1 and (iii) down-regulation of the phosphorylation of eEF2k.

The SREBP1 is of particular interest here because SREBP1 has recently been implicated in the insulin resistance of type 2 diabetes. It is well known that, in the liver of many insulin-resistant mouse models, insulin fails to suppress D-(+)-glucose production (gluconeogenesis) but continue to promote lipid synthesis. It is also known that mTORC1 down-regulates (activates or de-stabilizes) SREBP-1 and thereby uncouples lipogenesis from gluconeogenesis [25]. This down-regulation of the expression of SREBP1 by mTORC1 appears to be achieved at least in part by promoting its posttranslational processing via S6K1, which in turn leads to the increased transcription of genes involved in sterol and lipid biosynthesis and the oxidative arm of the pentosephosphate pathway $[26,27]$. mTORC1-mediated decrease in (or activation or de-stabilization of) the expression of SREBP-1 also appears to be necessary for lipogenesis induced by Akt [28]. In summary, our results suggested that the deficiency of D-(+)-glucose could suppress insulin resistance and restore insulin sensitivity by downregulating the phosphorylation of S6K1 and up-regulating (de-activating or stabilizing) the expression of SREBP1,
Deficiency of D-(+)-glucose or L-leucine - but not 4hydroxitamoxifen - up-regulates the expression of mitochondrial ATP Synthase $\alpha$ chain (ATP5A) in the Complex $V$ of respiratory oxidation-phosphorylation chain During our preliminary proteomic analysis of the hepatic proteins of leptin-deficient obese mice and long-lived dwarf mice, we observed that the expression of mitochondrial ATP5A protein was most significantly downregulated in the liver of leptin-deficient obese mice relative to the lean control mice. We also observed that ATP5A protein was most significantly up-regulated in the liver of long-lived Ames dwarf mice relative to the normal Ames mice.

Based on these findings, we decided to investigate and, in fact, reported, as described above in the results section, that the deficiency of D-(+)-glucose, L-leucine or L-methionine up-regulated the expression of mitochondrial ATP5A in the human MDA-MB-231 breast cancer cells in vitro as well.

As to the possible molecular mechanisms of the upregulation of ATP5A, we realized that almost no study was published in the literature. One exception was the study published in 2010, where authors speculated that, as wakefulness continues in mice, the maintenance of ATP becomes more challenging and likely to involve additional nuclear transcriptional mechanisms [29]. The authors further stated that, initially, the demand for increased ATP during wakefulness is met by increased activity of the mitochondrial respiratory oxidation-phosphorylation (OxPhos) system (including ATP5B and probably ATP5A as well). This would eventually lead to an increase in the production of reactive oxygen species (ROS) during extended wakefulness that would then lead to uncoupling with at least temporary decline in ATP and increase in AMP resulting in the activation (increased phosphorylation) of 5'-AMP-dependent protein kinase (AMPK).

This study [29] places the molecular basis of the metabolic up-regulation of the expression of ATP5A by the deficiency of $\mathrm{D}-(+)$-glucose or L-leucine at the AMPK, which is one of the essential components of the pathway \#2 in the upstream molecular signaling pathways of p27 expression.

\section{Deficiency of D-(+)-glucose or L-leucine - but not 4- hydroxitamoxifen - up-regulates the expression of mitochondrial SIRT3, one of the seven mammalian anti- aging and anti-metabolic sirtuins}

Mitochondrial SIRT3 is one of the seven mammalian sirtuins that are involved in anti-aging and other metabolic processes. Recently, it was reported that mitochondrial SIRT3 forms complex with and interacts with mitochondrial ATP5A [24]. Since SIRT3 is known to be present ubiquitously in the body, we speculated that 
SIRT3 could also be present in the human MDA-MB231 breast cancer cells in vitro and, in fact, as described in the results section above, we found that deficiency of D-(+)-glucose or L-leucine - but not 4-hydroxytamoxifen - up-regulated the expression of SIRT3 in these cells.

Sirtuins are a family of $\mathrm{NAD}^{+}$-dependent protein deacetylases that regulate cellular functions through deacetylation of a wide range of protein targets [24,30-34]. Overexpression of Sir2, the first gene discovered in this family, is able to extend the life span in various organisms. The anti-aging effects of human homologues of sirtuins, SIRT1-7, have also been suggested by animal and human studies.

The results of our study are consistent with the notion that deficiency of $\mathrm{D}-(+)$-glucose or L-leucine - but not 4-hydroxytamoxifen - could exert anti-aging and other metabolic effects through the pathway that involves AMPK, ATP5A and SIRT3. It has been reported, in fact, that the expression of mitochondrial SIRT3 may be upregulated in caloric restriction and down-regulated in obesity and diabetes $[35,36]$. It has also been reported that the activation (increased phosphorylation) of AMPK may lead to up-regulation of the expression of mitochondrial SIRT3 [37].

Thus, the origin of the metabolic up-regulation of the expression of mitochondrial SIRT3 by the deficiency of D-(+)-glucose or L-leucine could be traced to AMPK, which is again one of the essential components of the pathway \#2 in the upstream molecular signaling pathways of $\mathrm{p} 27$. expression.

\section{Conclusions}

Previously, we identified and reported four different upstream molecular signaling pathways - we called them pathway \#1, \#2, \#3 and \#4 - of the expression of p27 in human breast cancer cells in vitro. Based on the results presented above, we conclude that:

(a) 4-Hydroxitamoxifen uses primarily pathway \#1 to up-regulate the expression of p27. The pathway \#1 consists mainly of receptor tyrosine kinases (RTKs) and mammalian target of rapamycin complex 1 (mTORC1).

(b) Moderate increase in the concentration of D$(+)$-glucose is likely to use primarily pathway \#2 to down-regulate the expression of p27. The pathway \#2 consists mainly of 5'-AMP-activated protein kinase (AMPK) and $\mathrm{mTORC} 1$ protein kinase.

(c) Deficiency of D- $(+)$-glucose or L-leucine uses primarily pathway \#2 to up-regulate the expression of p27.

(d) Additionally, deficiency of D-(+)-glucose or L-leucine - but not 4-hydroxytamoxifen - also up-regulates the expression of mitochondrial ATP5A in the Complex V of respiratory oxidation-phosphorylation chain and mitochondrial anti-aging as well as anti-metabolic SIRT3.

\section{Methods}

\section{Reagents}

4-Hydroxytamoxifen, tamoxifen, D-(+)-glucose, and rotenone were obtained from Sigma-Aldrich (St. Louis, MO, USA). Compound $C$ and metformin were obtained from Calbiochem/EMD (San Diego, CA, USA). AICA riboside was purchased from Phoenix Pharmaceuticals, Inc. (Belmont, CA, USA). Dulbecco's Modified Eagle's Medium (DMEM) Labeling Kit was purchased initially from Chemicon International (Temecula, CA, USA) and later from EMD Millipore (Billerica, MA, USA).

The following antibodies were purchased from Cell Signaling Technology, Inc. (Danvers, MA, USA): namely (a) total 4E-BP1 and phospho-4E-BP1 (Thr37/46); (b) total S6K1 and phospho-S6K1 (Thr389); and (c) total eEF2k and phospho-eEF2k (Ser366). Additionally, the following antibodies were purchased from Santa Cruz Biotechnology, Inc. (Santa Cruz, CA, USA): namely (a) p27, (b) GAPDH, (c) ATP5A, (d) SIRT3, (e) SIRT1, (f) SREBP-1, and (g) HIF- $1 \alpha$.

\section{Cell Cultures}

Human MDA-MB-231 breast cancer cells (estrogen receptor (ER) and LKB1-double negative) were purchased from the American Type Culture Collection (Rockville, MD, USA). The cells were grown in Dulbecco's Modified Eagle's Medium (DMEM) containing $4.5 \mathrm{~g} / \mathrm{L}$ of $\mathrm{D}-(+)$-glucose, supplemented with $10 \%$ heat-inactivated FBS, 2\% L-glutamine, and antibiotics/ antimycotics. Incubation of the cells was carried out at $37^{\circ} \mathrm{C}$ in a $5 \% \mathrm{CO}_{2}$ humidified chamber. The cells were subcultured after trypsinization with $0.05 \%$ trypsin-0.02\% EDTA solution. The cells were always maintained below confluency and checked periodically for mycoplasmal infection by DNA fluorochrome staining.

\section{Plasmids}

Luciferase reporter plasmids containing one of the following proximal 5'-upstream regions of the $p 27$ gene were used to transfect the human MDA-MB-231 breast cancer cells: -1797 p27 (p27-Kpn I) [38], -774 p27 (p27Apa I) [38], and -575 p27 (p27-5'UTR) [4,8]. The control luciferase reporter plasmids not containing these inserts were also prepared and used to test if 24-hour treatment of the cells with DMSO, 4-hydroxytamoxifen, tamoxifen, excess $\mathrm{D}-(+)$-glucose, or the deficiency of D(+)-glucose, L-leucine, L-methionine, L-cysteine, or combination of L-methionine and L-cysteine was exerting any spurious effects on the backbone, rather than the insert, of the luciferase reporter plasmids. None of these treatments were found to exert any spurious effects on the backbone of the plasmids in the human MDA-MB-231 breast cancer cells. 


\section{Transfection and Luciferase Assay}

Transfections were performed according to the published protocol [39] using FuGENE 6 obtained from Roche Applied Science (Indianapolis, IN, USA). In brief, 24 hours before reporter transfection, the cells were seeded into a $60-\mathrm{mm}$ tissue culture dish at a density of $1.5 \times 10^{5}$ cells/dish and incubated at $37^{\circ} \mathrm{C}$ in a $5 \% \mathrm{CO} 2$ humidified chamber. Transfection of the luciferase reporter plasmid was then carried out with $1 \mu \mathrm{g}$ of luciferase reporter plasmid and $0.2 \mu \mathrm{g}$ of $\mathrm{pSV}-\beta$-galactosidase internal control plasmid (Promega, Madison, WI, USA) mixed with $3 \mu \mathrm{L}$ of FuGENE 6 solution in $3 \mathrm{~mL}$ of FBS-free DMEM supplemented with only $2 \% \mathrm{~L}$-glutamine. A minimum of 5 -hour incubation at $37^{\circ} \mathrm{C}$ was needed for transient transfection, followed by 18 -hour incubation in DMEM with 10\% FBS for recovery. The transfected cells were then starved in DMEM with $0.2 \%$ FBS for 24 hours. Subsequently, the resulting cells were cultured either (a) in the presence of DMSO, tamoxifen, or 4-hydroxytamoxifen in the regular DMEM with $0.2 \%$ FBS, (b) in the presence of a moderate increase in the concentration of D- $(+)$-glucose or (c) deficiency of D(+)-glucose, L-leucine, L-methionine, L-cysteine or combination of L-methionine and L-cysteine in the appropriately supplemented basal DMEM Labeling Kit as described in the figure legends. After 24 hours, the treated cells were collected and lysed using Reporter Lysis Buffer (Promega, Madison, WI) and the resulting cell lysates were assayed for luciferase activity using Luciferase Assay Kit (Promega, Madison, WI, USA) and TD20/20 Luminometer (Turner Designs, Sunnyvale, CA, USA). $\beta$-Galactosidase activity was measured using chlorophenol red- $\beta$-D-galactopyranoside (CPRG) (Sigma-Aldrich, St. Louis, MO, USA) as a substrate.

Each luciferase activity driven by a specific proximal 5 '-upstream region of the $p 27$ gene was normalized to $\beta$-galactosidase activity in order to control for variations in transfection efficiency.

As for the issue of whether the expression of p27 was regulated primarily at the level of translation, we performed the following three different studies:

(a) The various deletion constructs of -1797 p27-Kpn1 luciferase reporter plasmids were used to determine the core element of the activation of the proximal 5'upstream region $(-1797)$ of $p 27$ gene [1,2]. The results indicated that various nutritional and chemopreventive anti-cancer agents, including tamoxifen and 4-hydroxytamoxifen, activated the proximal 5'-upstream region $(-1797)$ of $\mathrm{p} 27$ gene through its 5 '-untranslated region (5'UTR) (-575). It is well established that this region mediates the cap-independent translation initiation of p27 mRNA [4-10].

(b) To investigate if -575 p27 (p27-5'UTR) contains any cryptic transcription factor binding sites - in other words, if the expression of p27 is regulated primarily at the level of transcription - the luciferase activity of the region was stimulated with 4-hydroxytamoxifen in the presence of an adequate dose of antibiotic actinomycin D [1,2]. Actinomycin D is a well-known inhibitor of transcription. The results indicated that the -575 p27 (5'-untranslated region (5'UTR)) is unlikely to contain any cryptic transcription factor binding sites. This assay was performed not only with tamoxifen and 4-hydroxytamoxifen, but also with many other anti-cancer agents.

(c) Depending on the cell types, it was observed from time to time that control vector expression was affected by each treatment and also there could be cell cycle effects probably changing with treatment. To exclude these possibilities, the p27 luciferase reporter vector that does not contain and insert of the specific proximal 5'upstream region of the $p 27$ gene was prepared and tested using the same anti-cancer agents and cell types $[1,2]$. In these exceptional cases, the following formula was used to correct this false increase in the relative luciferase activity:

Relative luciferase activity $(\%)=($ Experimental luciferase activity/Control luciferase activity $) \times 100$,

where,

(1) Experimental luciferase activity $=\{$ Test compound/None $\}$ Luciferase reporter vector containing a specific insert\},

(2) Control luciferase activity $=\{$ Test compound $/$ None\}\{Luciferase reporter vector $\underline{\text { NOT }}$ containing a specific promoter insert\}, and

(3) Test compound/None $=[\operatorname{Luc}($ Test $) / \beta$ Gal(Test) $] /$

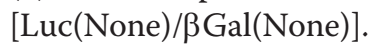

The human MDA-MB-231breast cancer cells that were used in this study did not present any of these exceptional problems. For additional information on this and related issues, please refer to the reference $\# 40$ [40].

\section{Western Immunoblot Analysis}

Western immunoblot analysis of the upstream molecular signaling pathways of the expression of p27 was performed using estrogen receptor (ER) and LKB1-double negative human MDA-MB-231 breast cancer cells in vitro. This analysis was performed without either transfecting the cells with various proximal 5'-upstream region of $p 27$ gene-luciferase reporter plasmids or adding any growth factors to avoid the artificial stimulation of the cell proliferation.

In brief, the cells were seeded at a density of $5.5 \times 10^{6}$ cells/dish into a $100-\mathrm{mm}$ tissue culture dish containing $10 \mathrm{~mL}$ of DMEM supplemented with $10 \%$ heat-inactivated fetal bovine serum (FBS), 2\% L-glutamine, and 
antibiotic/antimycotic solution and incubated at $37^{\circ} \mathrm{C}$ in a $5 \% \mathrm{CO}_{2}$ humidified chamber for 24 hours. After 24 hours, the cells were partially synchronized for another 24 hours in DMEM containing only $0.2 \%(\mathrm{v} / \mathrm{v})$ of FBS. Subsequently, the resulting cells were cultured either (a) in the presence of DMSO, tamoxifen, or 4-hydroxytamoxifen in the regular DMEM with $0.2 \%$ FBS or (b) in the presence or absence of D-(+)-glucose, L-leucine, Lmethionine, or L-cysteine in the appropriately supplemented basal DMEM Labeling Kit as described in the figure legends. After 24 hours, the cells were washed twice with cold $1 \times$ PBS and scraped in $1 \times$ RIPA Lysis Buffer (Santa Cruz Biotechnology, Santa Cruz, CA, USA) containing phenylmethylsulphonyl fluoride (PMSF), protease inhibitor cocktail, sodium orthovanadate and $50 \mathrm{mM} \mathrm{NaF}$. The cells were then sonicated and the supernatant was collected by centrifugation and stored at $-80^{\circ} \mathrm{C}$.

The supernatants $(60 \mu \mathrm{g}$ protein/lane) were applied to the SDS-PAGE and, after fractionation, proteins were transferred to nitrocellulose membrane, which was then blocked and incubated in a solution containing first primary antibody. After shaking overnight at $4^{\circ} \mathrm{C}$, the target proteins bound to the first primary antibody were further incubated in a solution containing alkaline phosphatase (AP)-conjugated secondary anti-immunoglobulin antibody and detected by chemiluminescence using TROPIX Western-Star Kit (Applied Biosystems, Foster City, CA, U.S.A.). After exposure to X-ray film, the blots were stripped using Western Re-Probe Solution (G-Biosciences, St. Louis, MO, U.S.A.), checked for removal of the chemiluminescence and then re-probed with second primary antibody.

Densitometric measurement of the intensity of the bands on the X-ray film was performed using UNSCAN-IT Gel \& Graph Digitizing Software Version 6.1 (Silk Scientific Corporation, Orem, UT, U.S.A.). Background corrections were done by four corner interpolation and optical density calculations were performed

\section{Statistical Analysis}

An experimental value with statistical significance of $\mathrm{P} \leq$ 0.05 compared to the control by $\mathrm{t}$ test is indicated as a single asterisk on top of the vertical bar.

\footnotetext{
List of abbreviations

Nonstandard abbreviations: p27: p27Kip1; p21: p21Cip1/Waf1; AMPK: 5'AMP-activated protein kinase; TSC: tuberous sclerosis complex; mTORC1: mammalian target of rapamycin complex 1; RTK: receptor tyrosine kinase; PI3K: phosphoinositide 3-kinase; PKB: protein kinase B; AMPK: 5'-AMPactivated protein kinase; MAPK: mitogen-activated protein kinase; MEK: mitogen-activated protein (MAP) kinase kinase; ERK: ERK MAP kinase; MNK: MAP kinase interacting kinase; $\mathrm{m}^{7} \mathrm{G}$ : 7-methylguanosine; CDK: cyclindependent kinase; CDI: cyclin-dependent kinase inhibitor; MNU: N-methyl-Nnitrosourea; ER: estrogen-receptor; 5'-UTR: 5'-untranslated region; IRES: internal ribosome entry site; DMSO: dimethyl sulfoxide; PGL3: pGL3 luciferase
}

reporter vector; AdoMet or SAM, S-(5'-adenosyl)-L-methionine; AdoHcy or SAH: S-(5'-adenosyl)-L-homocysteine; 4E-BP1: eukaryotic translation initiation factor 4E binding protein 1; S6K: p70 S6 kinase; AICAR: 5-amino-4imidazolecarboxamide aminoimidazole carboxamide ribonucleotide; Glc: D(+)-glucose; Ser: L-serine; Thr: L-threonine; Met: L-methionine; Cys: L-cysteine; Leu: L-leucine; Tyr: L-tyrosine; elF4E: eukaryotic translation initiation factor $4 \mathrm{E}$; UORF: 5'-upstream open reading frame; FBS: fetal bovine serum; DMEM: Dulbecco's modified Eagle's medium; EDTA: ethylenediaminetetraacetic acid;

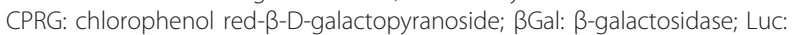
firefly luciferase; GAPDH: glyceraldehydes phosphate dehydrogenase; mTORC 1: mammalian target of rapamycin complex 1; HIF-1a: hypoxiainducible factor 1a; SREBP1: sterol regulatory element binding protein-1; eEF2k: eukaryotic elongation-factor-2 kinase; ATP5A: mitochondrial ATP Synthase a chain in the Complex $V$ of respiratory oxidation-phosphorylation chain; SIRT3: sirtuin 3; SIRT1: sirtuin 1; OxPhos: mitochondrial oxidationphosphorylation (repiratory electron transfer) chain, ROS, reactive oxygen species.

\section{Acknowledgements}

The author is grateful to Dr. Sakai (Kyoto Prefectural University of Medicine, Kyoto, Japan) for the gift of luciferase reporter plasmids -1797 p27Kip 1 (p27Kpn I) and-774 p27Kip1 (p27-Apa I) and Dr. Hengst (Max-Planck-Institut fur Biochemie, Martinsried bei Munchen, Germany) for the gift of luciferase reporter plasmid -575 p27Kip1 (p27-5'-UTR).

\section{Competing interests}

The author declares that they have no competing interests.

Received: 15 July 2011 Accepted: 9 September 2011

Published: 9 September 2011

\section{References}

1. Eto I: Nutritional and chemopreventive anti-cancer agents up-regulate expression of p27Kip1, a cyclin-dependent kinase inhibitor, in mouse JB6 epidermal and human MCF7, MDA-MB-321 and AU565 breast cancer cells. Cancer Cell Int 2006, 6:20, (pp. 1-19).

2. Eto I: Upstream molecular signaling pathways of p27(Kip1) expression: Effects of 4-hydroxytamoxifen, dexamethasone, and retinoic acids. Cancer Cell Int 2010, 10:3, (pp. 1-19).

3. Eto I: G1 cell cycle regulatory proteins in chemically induced rat mammary adenocarcinomas in vivo and tumor promotion-sensitive, -resistant, and transformed mouse epidermal cells in vitro. Cell Cycle 2003, 2:149-156.

4. Goepfert U, Kullmann M, Hengst L: Cell cycle-dependent translation of p27 involves a responsive element in its $5^{\prime}$-UTR that overlaps with a uORF. Hum Mol Genet 2003, 12:1767-1779.

5. Agrawal D, Hauser P, McPherson F, Dong F, Garcia A, Pledger WJ: Repression of p27(kip1) synthesis by PDGF in balb/c 3T3 cells. Mol Cell Biol 1996, 16:4327-4336.

6. Hengst L, Reed SI: Translational control of p27Kip1 accumulation during the cell cycle. Science 1996, 271:1861-1864.

7. Millard SS, Yan JS, Nguyen H, Pagano M, Kiyokawa H, Koff A: Enhanced ribosomal association of p27(Kip1) mRNA is a mechanism contributing to accumulation during growth arrest. J Biol Chem 1997, 272:7093-7098.

8. Kullmann M, Goepfert U, Siewe B, Hengst L: ELAV/Hu proteins inhibit p27 translation via an IRES element in the p27 5'UTR. Genes Dev 2002, 16:3087-3099.

9. Miskimins WK, Wang G, Hawkinson M, Miskimins R: Control of cyclindependent kinase inhibitor p27 expression by cap-independent translation. Mol Cell Biol 2001, 21:4960-4967.

10. Millard SS, Vidal A, Markus M, Koff A: A U-rich element in the $5^{\prime}$ untranslated region is necessary for the translation of p27 mRNA. Mol Cell Biol 2000, 20:5947-5959.

11. Pagano M, Tam SW, Theodoras AM, Beer-Romero P, Del Sal G, Chau V, Yew PR, Draetta GF, Rolfe M: Role of the ubiquitin-proteasome pathway in regulating abundance of the cyclin-dependent kinase inhibitor p27. Science 1995, 269:682-685.

12. Hara T, Kamura T, Nakayama K, Oshikawa K, Hatakeyama S: Degradation of p27(Kip1) at the $G(0)-G(1)$ transition mediated by a Skp2-independent ubiquitination pathway. J Biol Chem 2001, 276:48937-48943. 
13. Malek NP, Sundberg H, McGrew S, Nakayama K, Kyriakides TR, Roberts JM, Kyriakidis TR: A mouse knock-in model exposes sequential proteolytic pathways that regulate p27Kip1 in G1 and S phase. Nature 2001, 413:323-327.

14. Hengst L: A second RING to destroy p $27^{\text {Kip } 1 . ~ N a t u r e ~ C e l l ~ B i o l ~ 2004, ~}$ 6:1153-1155.

15. Soos TJ, Kiyokawa H, Yan JS, Rubin MS, Giordano A, DeBlasio A, Bottega S, Wong B, Mendelsohn J, Koff A: Formation of p27-CDK complexes during the human mitotic cell cycle. Cell Growth Differ 1996, 7:135-146.

16. Rodier G, Montagnoli A, Di Marcotullio L, Coulombe P, Draetta GF, Pagano M, Meloche S: p27 cytoplasmic localization is regulated by phosphorylation on Ser10 and is not a prerequisite for its proteolysis. EMBO J 2001, 20:6672-6682.

17. Viglietto G, Motti ML, Bruni P, Melillo RM, D'Alessio A, Califano D, Vinci F, Chiappetta G, Tsichlis P, Bellacosa A, Fusco A, Santoro M: Cytoplasmic relocalization and inhibition of the cyclin-dependent kinase inhibitor p27(Kip1) by PKB/Akt-mediated phosphorylation in breast cancer. Nat Med 2002, 8:1136-1144.

18. Liang J, Zubovitz J, Petrocelli T, Kotchetkov R, Connor MK, Han K, Lee JH, Ciarallo S, Catzavelos C, Beniston R, Liang J, Zubovitz J, Petrocelli T, Kotchetkov R, Connor MK, Han K, Lee JH, Ciarallo S, Catzavelos C, Beniston R, Franssen E, Slingerland JM: PKB/Akt phosphorylates p27, impairs nuclear import of p27 and opposes p27-mediated G1 arrest. Nat Med 2002, 8:1153-1160

19. Shin I, Yakes FM, Rojo F, Shin NY, Bakin AV, Baselga J, Arteaga CL: PKB/Akt mediates cell-cycle progression by phosphorylation of p27(Kip1) at threonine 157 and modulation of its cellular localization. Nat Med 2002, 8:1145-1152.

20. Connor MK, Kotchetkov R, Cariou S, Resch A, Lupetti R, Beniston RG Melchior F, Hengst L, Slingerland JM: CRM1/RAN-mediated nuclear export of p27 $7^{\text {Kip }}$ involves a nuclear export signal and links p27 export and proteolysis. Mol Biol Cell 2003, 14:201-213.

21. Ciarallo S, Subramanian V, Hung W, Lee JH, Kotchetkov R, Sandhu C, Milic A, Slingerland JM: Altered p27Kip1 phosphorylation, localization, and function in human epithelial cells resistant to transforming growth factor $\beta$-mediated G1 arrest. Mol Cell Biol 2002, 22:2993-3002.

22. Chu I, Sun J, Arnaout A, Kahn H, Hanna W, Narod S, Sun P, Tan CK, Hengst L, Slingerland J: p27 phosphorylation by Src regulates inhibition of cyclin E-Cdk2. Cell 2007, 128:281-294.

23. Kazi A, Carie A, Blaskovich MA, Bucher C, Thai V, Moulder S, Peng H, Carrico D, Pusateri E, J. Pledger WJ, Berndt N, Hamilton A, Sebti SM: Blockade of protein geranylgeranylation inhibits $\mathrm{Cdk2}$-dependent p27Kip1 phosphorylation on Thr187 and accumulates p27Kip1 in the nucleus: Implications for breast cancer therapy. Mol Cell Biol 2009, 29:2254-2263.

24. Law IKM, Liu L, Xu A, Lam KSL, Vanhoutte PM, Che CM, Leung PTY, Wang Y: Identification and characterization of proteins interacting with SIRT1 and SIRT3: implications in the anti-aging and metabolic effects of sirtuins. Proteomics 2009, 9:2444-2456.

25. Laplante M, Sabatini DM: mTORC1 activates SREBP-1c and uncouples lipogenesis from gluconeogenesis. Proc Natl Acad Sci US 2010, 107:3281-3282.

26. Sengupta S, Peterson TR, Sabatini DM: Regulation of the mTOR Complex 1 Pathway by Nutrients, Growth Factors, and Stress. Molecular Cell 2010, 40:310-322.

27. Düvel K, Yecies JL, Menon S, Raman P, Lipovsky Al, Souza AL, Triantafellow E, Ma Q, Gorski R, Cleaver S, Vander Heiden MG, Mackeigan JP, Finan PM, Clish CB, Murphy LO, Manning BD: Activation of a metabolic gene regulatory network downstream of mTOR complex. Molecular Cell 2010, 39:171-183.

28. Porstmann T, Santos CR, Griffiths B, Cully M, Wu M, Leevers S, Griffiths JR, Chung YL, Schulze A: SREBP activity Is regulated by MTORC1 and contributes to Akt-dependent cell growth. Cell Metab 2008, 8:224-236.

29. Naidoo N, Zhang L, Romer M, Cater JR, Scharf MT, Raymond J. Galante RJ, Pack Al: Changes in components of energy regulation in mouse cortex with Increases in wakefulness. SLEEP 2010, 33:889-900

30. Finley LWS, Carracedo A, Lee J, Souza A, Egia A, Zhang J, Teruya-Feldstein J, Moreira PI, Cardoso SM, Clish CB, Pandolf PP, Haigis MC: SIRT3 opposes reprogramming of cancer cell metabolism through HIF1a destabilization. Cancer Cell 2011, 19:416-428.
31. Giralt A, Hondares E, Villena JA, Ribas F, Díaz-Delfín J, Giralt M, Iglesias R, Villarroya F: Peroxisome proliferator-activated receptor- $\gamma$ coactivator-1a controls transcription of the Sirt3 gene, an essential component of the thermogenic brown adipocyte phenotype. J Biol Chem 2011, 286:16958-16966.

32. Kim HS, Patel K, Muldoon-Jacobs K, Bisht KS, Aykin-Burns NA, Pennington JD, van der Meer R, Nguyen P, Savage J, Owens KM, Vassilopoulos A, Ozden O, Park SH, Singh KK, Sarki A. Abdulkadir SA, Douglas R. Spitz DR, Chu-Xia Deng CX, Gius D: SIRT3 Is a mitochondrialocalized tumor suppressor required for maintenance of mitochondrial integrity and metabolism during stress. Cancer Cell 2010, 17:41-52.

33. Kong X, Wang R, Xue Y, Liu X, Zhang H, Chen Y, Fang F, Chang Y: Sirtuin 3, a new target of PGC-1a, plays an important role in the suppression of ROS and mitochondrial biogenesis. PLOS ONE 2010, 5:e11707.

34. Liu Y, Zhang D, Chen D: SIRT3: Striking at the heart of aging. Aging 2010, 12:914-923.

35. Choudhury M, Jonscher KR, Friedman JE: Reduced mitochondrial function in obesity-associated fatty liver: SIRT3 takes on the fat. AGING 2011, 3:175-178.

36. Huang JY, Hirschey MD, Shimazu T, Ho L, Verdin E: Mitochondrial sirtuins. Biochimica et Biophysica Acta (BBA) - Proteins \& Proteomics 2010, 1804:1645-1651.

37. Palacios OM, Carmona JJ, Michan S, Ke KY, Manabe Y, Ward III, Goodyear $\mathrm{U}$, Tong Q: Diet and exercise signals regulate SIRT3 and activate AMPK and PGC-1a in skeletal muscle. AGING 2009, 1:771-783.

38. Minami S, Ohtani-Fujita N, Igata E, Tamaki T, Sakai T: Molecular cloning and characterization of the human $\mathrm{p} 27^{\text {Kip } 1}$ gene promoter. FEBS Lett 1997, 411:1-6.

39. Hsu TC, Nair R, Tulsian P, Camalier CE, Hegamyer GA, Young MR, Colburn NH: Transformation nonresponsive cells owe their resistance to lack of p65/nuclear factor-KB activation. Cancer Res 2001, 61:4160-4168.

40. Vidal A, S. Millard S, Miller JP, Koff A: Rho activity can alter the translation of p27 mRNA and Is important for RasV12-induced transformation in a manner dependent on p27 status. J Biol Chem 2002, 277:16433-16440.

\section{doi:10.1186/1475-2867-11-31}

Cite this article as: Eto: Upstream molecular signaling pathways of p27 (Kip1) expression in human breast cancer cells in vitro: differential effects of 4-hydroxytamoxifen and deficiency of either D-(+)-glucose or L-leucine. Cancer Cell International 2011 11:31.

\section{Submit your next manuscript to BioMed Central and take full advantage of:}

- Convenient online submission

- Thorough peer review

- No space constraints or color figure charges

- Immediate publication on acceptance

- Inclusion in PubMed, CAS, Scopus and Google Scholar

- Research which is freely available for redistribution

Submit your manuscript at www.biomedcentral.com/submit
Ciomed Central 